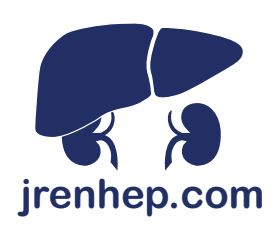

ORIGINAL ARTICLE

\title{
Outcomes of Albumin Use in the Treatment of Acute Hepatorenal Disorders: A Single Center Experience
}

\author{
Krishna Pothugunta ${ }^{1}$, Santhi Voora ${ }^{1}$, Holly Kramer $^{1-3}$, Anil K. Bidani ${ }^{1,3}$, Kavitha Vellanki ${ }^{1,3}$ \\ ${ }^{1}$ Division of Nephrology and Hypertension, Department of Medicine, Loyola University Chicago, Maywood, IL, USA; ${ }^{2}$ Department of Public \\ Health Sciences, Loyola University Chicago, Maywood, IL, USA; ${ }^{3}$ Hines Veterans Affair Medical Center, Hines, IL, USA
}

\begin{abstract}
Intravenous albumin is recommended for hepatorenal disorders (HRD), but individuals who do not recover renal function may be at a high risk for pulmonary edema. We reviewed outcomes by the amount of albumin infused in 93 patients not receiving dialysis at admission but being treated with intravenous albumin for acute HRD at our institution. Absence of renal recovery was defined as no decrease in serum creatinine and requirement of dialysis during hospitalization, and partial renal recovery was defined as a decrease in serum creatinine but not to prehospitalization levels. Associations of clinical factors including total albumin infused, presence of renal recovery, and oliguria with the development of pulmonary edema during hospitalization were determined using logistic regression. Of the 93 patients, 20 patients had complete renal recovery, 17 patients had partial renal recovery, and 56 patients showed no renal recovery. Most patients received 300-600 g of albumin. Overall, 47.3\% of patients developed pulmonary edema $(n=44)$, but the risk was $75 \%$ in patients with oliguria on presentation and no renal recovery versus $17 \%$ in those with no oliguria and complete renal recovery $(\mathrm{P}<0.001)$. In the logistic regression model, oliguria $(3.32 ; 95 \%$ confidence interval $[\mathrm{CI}]$ : $1.12,9.81)$ and no renal recovery $(3.38 ; 95 \%$ CI: $1.24,9.16)$ were each associated with higher odds of pulmonary edema after adjustment for covariates. No association was noted between total albumin infused and pulmonary edema. In summary, absence of renal recovery and oliguria in patients with HRD receiving intravenous albumin is associated with a higher risk of pulmonary edema.
\end{abstract}

Keywords: acute renal failure; albumin; cirrhosis; hepatorenal syndrome; pulmonary edema

Received: 26 October 2016; Accepted after revision: 08 December 2016; Published: 03 February 2017.

Author for correspondence: Holly Kramer, Department of Medicine, Loyola University Medical Center, 2160 S. First Avenue, Maywood, IL 60153, USA. Email: hkramer@1umc.edu

How to cite: Pothugunta K et al. Outcomes of albumin use in the treatment of acute hepatorenal disorders: a single center experience. J Ren Hepat Disord 2017;1(1):5-10.

DOI: http://dx.doi.org/10.15586/jrenhep.2017.2

Copyright: Pothugunta $\mathrm{K}$ et al.

License: This open access article is licensed under Creative Commons Attribution 4.0 International (CC BY 4.0). http://creativecommons.org/licenses/by/4.0

\section{Introduction}

Intravenous albumin plus midodrine and octreotide are recommended for the treatment of type I hepatorenal syndrome (HRS) (1). In clinical practice, albumin use is not just limited to type I HRS and is used in the setting of any acute renal failure (ARF) with underlying cirrhosis (hepatorenal disorders, or HRD) for volume expansion. In 1996, the
International Club of Ascites proposed a definition and diagnostic criteria for HRS (2), which was later revised in 2007 with albumin replacing normal saline for volume replacement (3). The recommended dose of albumin for volume resuscitation is $1 \mathrm{~g} / \mathrm{kg}$ of body weight per day with up to a maximum of $100 \mathrm{~g} /$ day; however, the evidence for this threshold is not supported by clinical trials. Volume resuscitation with albumin 
infusions in cirrhosis is expected to increase total body volume and circulatory function with resultant improvement in renal function (4). It is also thought to reduce the formation of ascites and edema by increasing the microvascular oncotic pressure, but the pathophysiological basis and evidence supporting this remains controversial $(5,6)$.

The distribution of infused albumin between intravascular and extravascular compartments depends on the transcapillary membrane permeability, which is dependent on multiple factors, including intravascular volume status, and comorbid conditions such as hypertension, diabetes, heart failure, and infections $(7,8)$. Studies involving human volunteers have shown that rapid increases in plasma volume that occur immediately with albumin infusions are not seen with repeated infusions despite increasing serum albumin levels (9). Most importantly, response to albumin infusions varies across individuals with cirrhosis, and intravascular volume does not consistently rise in all cirrhotic patients $(10,11)$. Earlier studies have reported cases of increasing pleural effusions, development of pulmonary edema, and heart failure and rupture of esophageal varices with albumin infusions in cirrhotic patients (12). However, recent guidelines $(1,13)$ poorly address the potential side effects of continued albumin infusions in cirrhotic patients with compromised renal function, where volume status is difficult to determine. We retrospectively reviewed the incidence of new onset pulmonary edema as well as patient outcomes in cirrhotic patients who received albumin infusions as part of the treatment for acute HRD at our university medical center. We hypothesized that oliguria is associated with a significantly increased risk of pulmonary edema in patients with HRD receiving intravenous albumin.

\section{Materials and Methods}

\section{Study population}

We conducted a retrospective chart review of all cirrhotic patients who were admitted to our institution between 2011 and 2013 with ARF and received albumin as part of management of acute HRD. Diagnostic codes (ICD-9) for cirrhosis (571, 571.2, 571.5, and 571.6), HRS (572.4), and ARF (584 and 584.9) were used to identify patients for the study. All identified charts were then manually reviewed to confirm the diagnosis of cirrhosis and ARF and that albumin was given as part of management of acute HRD (verified by physician documentation in chart). A total of 115 cirrhotic patients who were admitted between January 2011 and December 2013 were identified. After excluding patients who had an abnormal chest x-ray (CXR), were intubated or were dialysis dependent at admission, or were transferred to another hospital for care, a total of 93 patients were included in the final analysis. All 93 patients had clinically attributed HRD as the etiology of ARF, with no evidence of urinary tract obstruction or primary glomerular disease by clinical criteria. The study was approved by the Institutional
Review Board of Loyola University Chicago's Health Sciences Campus.

Information collected from the electronic medical record included age, sex, cause of liver disease, Model for End-Stage Liver Disease (MELD) score, serum creatinine at admission and at 72 hours after admission, urine output (UOP) during the first 24 hours of hospitalization, urine electrolytes before and after treatment, dialysis start date, presence of pulmonary edema on CXR, total amount of albumin administered during the hospital stay and prior to the development of pulmonary edema, and need for endotracheal intubation. Albumin infusions contained $4 \%$ albumin at initial presentation and $25 \%$ albumin at subsequent infusions. The dose varied from $100 \mathrm{ml}$ twice daily to $100 \mathrm{ml}$ thrice daily based on physician discretion. Incidence of renal recovery was defined as complete renal recovery (serum creatinine decreasing to prehospitalization baseline values), partial renal recovery (serum creatinine decreasing but not back to prehospitalization baseline values), and absence of renal recovery (no decrease in serum creatinine and requirement of dialysis during hospitalization). Pulmonary edema was defined as the presence of bilateral infiltrates on CXR in the absence of clinically suspected acute respiratory distress syndrome.

\section{Statistical analyses}

Characteristics of the study population by pulmonary edema status were compared using Fisher's exact test to compare categorical variables, and unpaired $t$-tests were used to compare continuous variables with a normal distribution. Nonparametric variables were compared using the Wilcoxon Rank-Sum Test. The percentage of patients with pulmonary edema was plotted by the presence of complete or partial renal recovery and by oliguria status at admission. To determine significant differences across categories of renal recovery and oliguria status, a chi-square test for linear trend was used. Logistic regression models were fitted to examine the association of pulmonary edema with total albumin infused and renal recovery status while simultaneously adjusting for age, peak serum creatinine, MELD score, and oliguria on presentation. These covariates were chosen based on a backward selection logistic regression model which included age, MELD score, initial serum albumin and creatinine, peak serum albumin and creatinine, total albumin infused, diuretic use during the first 24 hours of admission, oliguria during the first 24 hours after admission, and renal recovery status (no, partial, and complete). $\mathrm{P}<0.05$ was considered statistically significant. Analyses were completed using STATA/IC 13.1 (StataCorp LP, College Station, TX, USA).

\section{Results}

A total of 93 patients had clinically attributed HRS as the etiology of ARF (HRD). The mean age of the patients was 57.9 years with a mean MELD score of 29 (range: 145-58), 
mean serum albumin of 2.37 (range: $0.5-3.6$ ), and mean serum creatinine of $2.35 \mathrm{mg} / \mathrm{dl}$ (range: $0.77-12.8 \mathrm{mg} / \mathrm{dl}$ ) on presentation. Oliguria (defined as less than $500 \mathrm{ml}$ of UOP in the first 24 hours after admission) was present in $29 \%$ of the patients. Renal recovery status was complete and partial in 20 and 17 patients, respectively, while 56 patients had no renal recovery. The amount of albumin infused ranged from 300 to $600 \mathrm{~g}$ of albumin in 52 patients while four patients received more than $1000 \mathrm{~g}$ of albumin during the hospital course. Peak serum albumin achieved during hospitalization ranged from 2.1 to $9.4 \mathrm{~g} / \mathrm{dl}$ with a mean of $3.7 \mathrm{~g} / \mathrm{dl}$, and 35 of 93 patients had a peak serum albumin of $4.0 \mathrm{~g} / \mathrm{dl}$ or higher.

The baseline characteristics by renal recovery status are shown in Table 1. The presence or absence of oliguria, age, and development of pulmonary edema differed significantly by renal recovery status while the presenting MELD score, serum creatinine, or the etiology of liver disease did not. Of the 20 patients with complete renal recovery, 7 patients died by the end of the study period, 10 were alive, and 3 received an orthotropic liver transplant (OLT). In the partial renal recovery group $(\mathrm{N}=17)$, a total of 12 patients died, four received organ transplant (2 OLT and 2 simultaneous liverkidney transplants), and one patient remained alive without dialysis at the end of the study period. Of the 56 patients that had no renal recovery, 12 died without receiving dialysis, one patient received a simultaneous liver-kidney transplant and the remaining 43 required dialysis. Of the 43 patients that required dialysis, 23 died, 4 received OLT, 5 received a simultaneous liver-kidney transplant, and the rest remained alive on dialysis at the end of the study period.

The risk of new onset pulmonary edema during the hospitalization was $47 \%(n=44)$. The baseline characteristics by the development of pulmonary edema are shown in Table 2. Both oliguria on presentation $(15.1 \%$ vs. $43.4 \%, \mathrm{P}=0.002)$ and the presence of partial or complete renal recovery $(52.7 \%$ vs. $23.7 \%, \mathrm{P}=0.002)$ differed significantly by the development of pulmonary edema. When stratified by renal outcomes and oliguria, there was a statistically significant linear trend in the incidence of pulmonary edema (Figure 1) by renal recovery and oliguria status $(\mathrm{P}<0.001)$, with the highest risk noted in those with oliguria and no renal recovery $(60.7 \%)$. A total of 29 patients required mechanical

Table 1. Baseline characteristics of patients with hepatorenal disorders receiving intravenous albumin $(n=93)$

\begin{tabular}{|c|c|c|c|c|}
\hline Characteristic & $\begin{array}{c}\text { Total } \\
(\mathrm{N}=93)\end{array}$ & $\begin{array}{l}\text { Complete renal } \\
\text { recovery }(\mathrm{N}=\mathbf{2 0})\end{array}$ & $\begin{array}{c}\text { Partial renal } \\
\text { recovery }(\mathrm{N}=17)\end{array}$ & $\begin{array}{c}\text { No renal } \\
\text { recovery }(N=56)\end{array}$ \\
\hline Age (years) & $57.9(10.1)$ & $54.8(10.5)$ & $63.5(9.7)$ & $57.3(9.6)^{*}$ \\
\hline$\%$ Male & 52.2 & 50 & 47 & 55 \\
\hline+ MELD score & $29.0(14.9,58.0)$ & $27.7(20.4,35.9)$ & $32.5(26.7-33.1)$ & $29.4(24.7,39.7)$ \\
\hline \multicolumn{5}{|l|}{ Liver disease etiology } \\
\hline Alcoholic & 52.7 & 50.5 & 70.0 & 48.2 \\
\hline $\mathrm{HCV}$ & 15.1 & 15.1 & 0 & 19.6 \\
\hline$\%$ NASH & 21.5 & 15.1 & 18.0 & 24.7 \\
\hline Other & 10.8 & 19.3 & 12.0 & 7.5 \\
\hline $\begin{array}{l}\text { Initial serum } \mathrm{Cr}(\mathrm{mg} / \mathrm{dl}) \\
\text { (mean with } \mathrm{SD})\end{array}$ & $2.90(1.77)$ & $3.49(2.01)$ & $3.73(2.73)$ & $2.44(1.03)$ \\
\hline $\begin{array}{l}\text { Peak creatinine }(\mathrm{mg} / \mathrm{dl}) \\
\text { (mean with } \mathrm{SD})\end{array}$ & $4.74(2.01)$ & $4.14(2.06)$ & $5.45(2.28)$ & $4.72(1.88)$ \\
\hline Oliguria & $29.0 \%$ & $25 \%$ & $29.4 \%$ & $30.4 \% * *$ \\
\hline $\begin{array}{l}\text { Albumin baseline (g/dl) } \\
\text { (mean with SD) }\end{array}$ & $2.37(0.61)$ & $2.39(0.51)$ & $2.49(0.60)$ & $2.36(0.65)$ \\
\hline $\begin{array}{l}\text { Peak albumin }(\mathrm{g} / \mathrm{dl}) \\
\text { (mean with SD) }\end{array}$ & $3.74(0.94)$ & $3.42(0.57)$ & $3.81(0.99)$ & $3.83(1.02)$ \\
\hline +Total albumin infused (g) & $325(200,550)$ & $350(218.8,531.25)$ & $275(170,537.5)$ & $325(200,687.5)$ \\
\hline$\%$ Pulmonary edema & 47.3 & 20.4 & 37.6 & $60.2 * *$ \\
\hline
\end{tabular}

MELD, Model for End-Stage Liver Disease; HCV, Hepatitis C Virus; NASH, Non-Alcoholic SteatoHepatitis; SD, standard deviation. +values shown as median (interquartile range); ${ }^{*} \mathrm{P}<0.001$ for oliguria and pulmonary edema; ${ }^{\mathrm{P}}=0.02$ for age. 
Table 2. Comparison of baseline characteristics of patients with hepatorenal disorders receiving intravenous albumin by the development of pulmonary edema $(n=93)$

\begin{tabular}{|c|c|c|c|}
\hline Characteristic & No pulmonary edema $(n=49)$ & Pulmonary edema $(n=44)$ & $\mathbf{P}$ \\
\hline Age & $61.1(10.2)$ & $59.6(10.6)$ & 0.7 \\
\hline$\%$ Male & 30.5 & $54.3 \%$ & 0.4 \\
\hline MELD score & $27.8(15.6-58.0)$ & $32.6(14.9-51.4)$ & 0.2 \\
\hline Initial serum $\mathrm{Cr}(\mathrm{mg} / \mathrm{dl})$ & $2.44(1.03-12.84)$ & $2.22(0.77-5.93)$ & 0.3 \\
\hline Peak creatinine (mg/dl) & $4.25(1.77-12.84)$ & $4.98(2.64-10.18)$ & 0.6 \\
\hline$\%$ Oliguria & 15.1 & 43.4 & 0.002 \\
\hline Initial albumin (g/dl) & $2.30(1.2-3.6)$ & $2.35(0.5-3.5)$ & 0.6 \\
\hline Peak albumin (g/dl) & $3.7(2.1-4.51)$ & $3.65(2.1-9.4)$ & 0.4 \\
\hline $\begin{array}{l}\% \text { Partial or complete renal } \\
\text { recovery }\end{array}$ & 52.7 & 23.7 & 0.002 \\
\hline$\%$ Paracentesis & 70.2 & 56.5 & 0.1 \\
\hline
\end{tabular}

MELD, Model for End-Stage Liver Disease.

intubation during the hospital course of which 12 patients had no recovery of renal function. On univariate analysis, the presenting MELD score, serum creatinine, oliguria, and renal recovery status showed significant associations with the development of pulmonary edema (Table 3). After adjustment for age, and MELD score, both oliguria (3.32; 95\% confidence interval $[\mathrm{CI}]: 1.12,9.81)$ and no renal recovery (3.38; 95\% CI: $1.24,9.16)$ were significantly associated with higher odds of developing pulmonary edema.

\section{Discussion}

Our study examined the incidence of new onset pulmonary edema with albumin infusions in patients with HRD. While traditionally HRS is subdivided into two types (14), type I and type II, based on rapidity of deterioration of renal function, a recent consensus conference has proposed HRD as a term to describe concurrent renal dysfunction in the setting of advanced cirrhosis (13). We chose to use the term acute HRD for our study as albumin infusions are not just limited

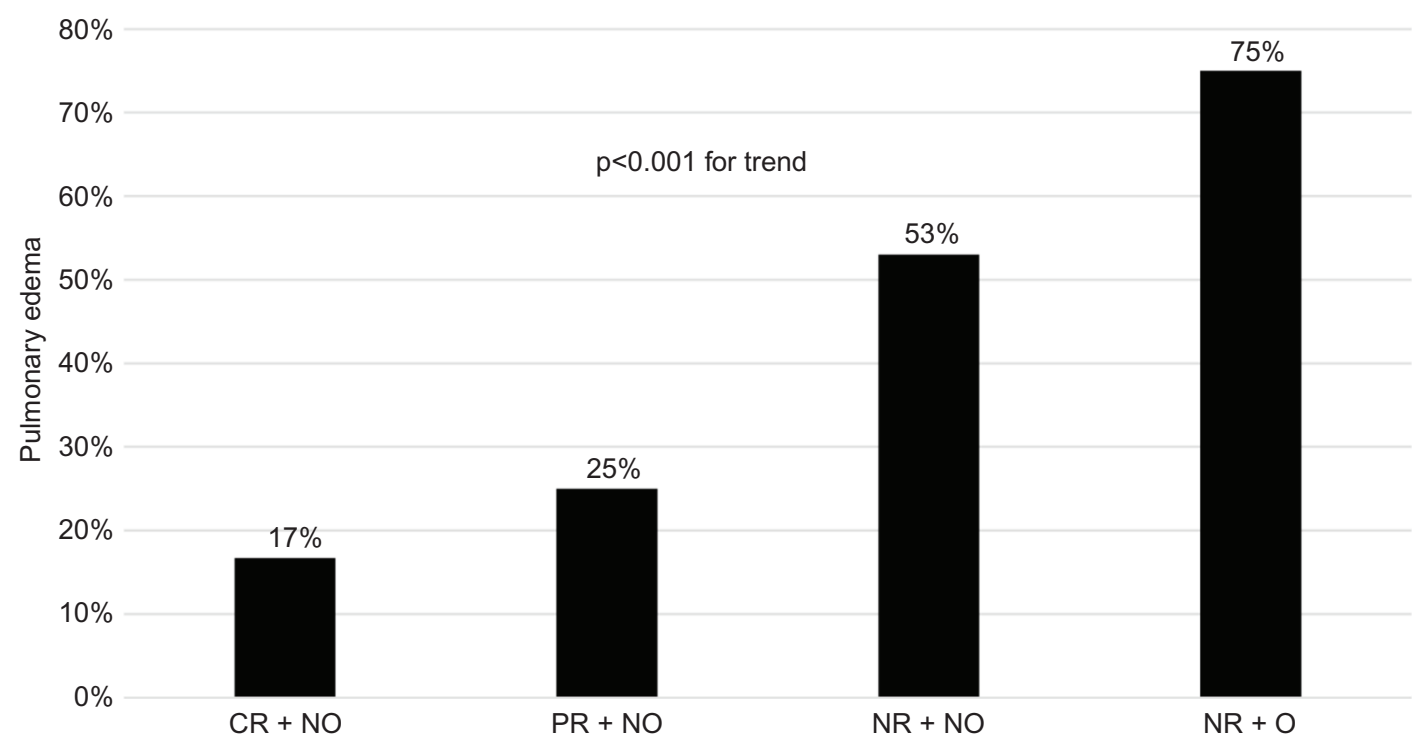

Figure 1. Risk of new onset pulmonary edema stratified by renal recovery status and oliguria in 93 patients with hepatorenal disorders receiving intravenous albumin. $\mathrm{CR}$, complete recovery; NO, nonoliguric; NR, no recovery; O, oliguric; PR, partial recovery. 
Table 3. Univariate and multivariable adjusted associations between clinical factors and pulmonary edema among adults with hepatorenal disorders

\begin{tabular}{|c|c|c|}
\hline & $\begin{array}{l}\text { Univariate odds ratio } \\
\qquad(95 \% \mathrm{CI})\end{array}$ & $\begin{array}{l}\text { Multivariate odds ratio } \\
\qquad(95 \% \mathrm{CI})\end{array}$ \\
\hline Age & $0.97(0.94,1.02)$ & $0.99(0.94,1.03)$ \\
\hline MELD score & $1.05(0.99,1.10)$ & $1.04(0.98,1.09)$ \\
\hline Initial serum albumin & $0.77(0.39,1.51)$ & - \\
\hline Peak serum albumin & $1.05(0.68,1.63)$ & - \\
\hline Total albumin infused & $1.00(0.99,1.01)$ & - \\
\hline Use of diuretics at admission & $1.39(0.58,3.30)$ & - \\
\hline Oliguria & $5.00(1.85,13.53)$ & $3.32(1.12,9.81)$ \\
\hline Initial serum creatinine & $0.95(0.75,1.21)$ & - \\
\hline Peak serum creatinine & $1.45(1.12,1.87)$ & $1.14(0.83-1.54)$ \\
\hline No renal recovery & $5.18(2.05,13.08)$ & $3.38(1.24-9.16)$ \\
\hline
\end{tabular}

MELD, Model for End-Stage Liver Disease; CI, confidence interval.

Variables in the multivariate analysis were selected by backward selection with all variables in univariate analysis fitted in the model.

to type I HRS in clinical practice. Liver transplantation is the treatment of choice for HRD but pharmacological treatment with albumin infusions for volume replacement is also widely recommended (1, 13-19).

Volume overload with continued albumin infusions is of particular concern in cirrhotic patients. Although the guidelines from the International Club of Ascites acknowledge the risk of pulmonary edema, the risk is considered to be low (3). We noted a high risk of pulmonary edema among adults with acute HRD receiving intravenous albumin, and this risk was the highest in patients with oliguria and absence of renal recovery. The presenting MELD score or serum albumin was not associated with a risk of pulmonary edema. Hence, we postulate that new onset pulmonary edema was from volume overload in the setting of continued albumin infusions. The graded increase in the incidence of pulmonary edema when stratified by the presence of oliguria or renal response to treatment further supports our conclusion.

In our study, the amount of albumin infused was not associated with renal recovery status or the development of pulmonary edema. This could be related to the variable response to albumin infusions based on intravascular volume status on presentation. Almost all patients in our study did not have invasive monitoring of hemodynamic parameters which is the case in routine clinical practice. Also, there was a wide variation in the total amount of albumin given per day with the total amount of albumin infused varying between 150 and $1100 \mathrm{~g}$, with one patient having a peak serum albumin as high as $9.4 \mathrm{~g} / \mathrm{dl}$ on multiple readings during the hospital course. A lag period between albumin infusions and CXR findings and/or symptoms of pulmonary edema could be a major confounder when trying to determine a correlation between the amount of albumin infused and the development of pulmonary edema.

The limitations of our study include the observational design and the small sample size. Hemodynamic monitoring was not performed in patients, and we do not have information on the baseline volume status of the patients with acute HRD. Patients were not weighed daily and so we do not have information on change in their weight from admission to the development of pulmonary edema. Oliguria on presentation was determined by physician documentation in the chart and verified from the outputs documented in the chart on admission. However, documentation of total fluid intake versus UOP may not have been accurately recorded. Pulmonary edema was defined by new CXR findings. The dose and duration of intravenous albumin was determined by the treating physician. Due to the small number of cases of pulmonary edema, we could not control for a large number of potential confounders, and residual confounding is possible.

\section{Conclusion}

In our retrospective study, the risk of new onset pulmonary edema was high in oliguric patients whose renal function did not improve with intravenous albumin. Caution should be exercised while giving continued albumin infusions to patients with oliguria, and close monitoring of volume status should be mandated to avoid the risk of pulmonary edema. 


\section{Acknowledgments}

There was no funding for this research. Data were presented as poster at the American Society of Nephrology meeting, November 2014, Philadelphia, PA (Dr. Pothugunta).

\section{Conflict of Interest}

The authors declare no conflicts of interest with respect to research, authorship, and/or publication of this article.

\section{References}

1. Bruce AR. AASLD practice guideline. Management of adult patients with ascites due to cirrhosis: Update 2012. Hepatology. 2009;49(6):2087-107. http://dx.doi.org/10.1002/hep.22853

2. Arroyo V, Gines P, Gerbes AL, Dudley FJ, Gentilini P, Laffi G, et al. Definition and diagnostic criteria of refractory ascites and hepatorenal syndrome in cirrhosis. International Ascites Club. Hepatology. 1996 Jan;23(1):164-76. http://dx.doi.org/10.1002/ hep. 510230122

3. Salerno F, Gerbes A, Gines P, Wong F, Arroyo V. Diagnosis, prevention and treatment of hepatorenal syndrome in cirrhosis. Gut. 2007 Sep;56(9):1310-18.

4. Runyon BA. Historical aspects of treatment of patients with cirrhosis and ascites. Semin Liver Dis. 1997;17(3):163-75. http://dx. doi.org/10.1055/s-2007-1007195

5. Romanelli RG, La Villa G, Barletta G, Vizzutti F, Lanini F, Arena $\mathrm{U}$, et al. Long-term albumin infusion improves survival in patients with cirrhosis and ascites: An unblinded randomized trial. World J Gastroenterol. 2006 Mar;12(9):1403-7. http://dx. doi.org/10.3748/wjg.v12.i9.1403

6. Gines P, Arroyo V. Is there still need for albumin infusions to treat patients with liver disease? Gut. 2000 May;46(5):588-90. http://dx.doi.org/10.1136/gut.46.5.588

7. Boldt J. Use of albumin: An update. Br J Anaesth. 2010 Mar;104 (3):276-84. http://dx.doi.org/10.1093/bja/aep393

8. Kumar R, Kumar S, Lata S. Albumin infusion may deleteriously promote extracellular fluid overload without improving circulating hypovolemia in patients of advanced cirrhosis with diabetes mellitus and sepsis. Med Hypotheses. 2013 Apr;80(4):452-5. http://dx.doi.org/10.1016/j.mehy.2012.12.039

9. Peters T Jr. All about albumIn: Biochemistry, genetics, and medical applications. San Diego, CA: Academic Press; 1996.
10. Henriksen JH, Kisza-Kanowitz M, Bendsten F, Moller S. Review article: Volume expansion in patients with cirrhosis. Aliment Pharmacol Ther. 2002;16(Suppl. 5):12-23. http://dx. doi.org/10.1046/j.1365-2036.16.s5.3.x

11. Brinch K, Moller S, Bendtsen F, Becker U, Henriksen J. Plasma volume expansion by albumin in cirrhosis. Relation to blood volume distribution, arterial compliance and severity of disease. J Hepatol. 2003 Jul;39(1):24-31. http://dx.doi.org/10.1016/S01688278(03)00160-0

12. Faloon WW, Eckhardt RD, Murphy L, Cooper AM, Davidson CS. An evaluation of human serum albumin in the treatment of cirrhosis of the liver. J Clin Invest. 1949 Jul;28(4):583-94. http:// dx.doi.org/10.1172/JCI102108

13. Nadim K, Kellum J, Davenport A, Wong F, Davis C, Pannu N, et al. Hepatorenal syndrome: The 8th International Consensus Conference of the Acute Dialysis Quality Initiative (ADQI) Group. Crit Care. 2012 Feb;16(1):R23. http://dx.doi.org/10. 1186/cc11188

14. Gines P, Schrier RW. Renal failure in cirrhosis. N Engl J Med. 2009 Jan;361(1):1279-90. http://dx.doi.org/10.1056/NEJMra08 09139

15. Sort P, Navasa M, Arroyo V, Aldeguer X, Louvet A, Plessier A, et al. Effect of intravenous albumin on renal impairment and mortality in patients with cirrhosis and spontaneous bacterial peritonitis. N Engl J Med. 1999 Apr;341(4):403-9. http://dx. doi.org/10.1056/NEJM199908053410603

16. Angeli P, Volpin R, Gerunda G, Craighero R, Roner P, Merenda R, et al. Reversal of type I hepatorenal syndrome with the administration of midodrine and octreotide. Hepatology. 1999 Jun;29 (6): 1690-7. http://dx.doi.org/10.1002/hep.510290629

17. Wong F, Pantera L, Sniderman K. Midodrine, octreotide, albumin, and TIPS in selected patients with cirrhosis and type 1 hepatorenal syndrome. Hepatology. 2004 Jul;40(1):55-64. http://dx. doi.org/10.1002/hep. 20262

18. Esrailian E, Pantangco ER, Kyulo NL, Hu K-Q, Runyon BA. Octreotide/midodrine therapy significantly improves renal function and 30 day survival in patients with type I hepatorenal syndrome. Dig Dis Sci. 2007 Mar;52(3):742-48. http://dx.doi.org/10. 1007/s10620-006-9312-0

19. Skagen C, Einstein M, Michael RL, Adnan S. Combination treatment with octreotide, midodrine and albumin improves mortality in patients with type I and type II hepatorenal syndrome. J Clin Gastroenterol. 2009 Aug;43(7):680-5. http://dx. doi.org/10.1097/MCG.0b013e318188947c 